\title{
Identificação dos impactos socioambientais decorrentes da implantação da estação de tratamento de esgoto no Semiárido Paraibano
}

\author{
Identification of socio-environmental impacts resulting from the implementation of the sewage
}

treatment station in the Semi-arid Region of Paraíba

Identificación de los impactos sociales y ambientales derivados de la implementación de la planta de tratamiento de aguas residuales en la Región Semiárida de Paraíba

\section{Resumo}

A presente pesquisa se propõe identificar os impactos positivos e/ou negativos decorrentes da implantação de uma Estação de Tratamento de Esgoto (ETE) sob a perspectiva da comunidade circunvizinha no município de Sumé, Paraíba. Para tanto, a ETE foi escolhida por possuir relevância no cenário social/local, uma vez que esse empreendimento tem o potencial de geração de impactos no âmbito social e ambiental. A área de estudo, foi delimitada considerando-se o raio de $1 \mathrm{~km}$ do entorno da ETE, com o intuito de caracterizar o número de residências que compõe a vizinhança. As residências avaliadas encontram-se situadas em diferentes pontos estratégicos, como forma de averiguar a sua influência na concepção dos entrevistados em função do local em que residem. Após a delimitação da área de abrangência do estudo, foi possível aplicar o questionário sob a forma de uma entrevista semiestruturada junto à comunidade do entorno da ETE, a fim de servir de instrumento avaliador da percepção da população acerca dos impactos socioambientais ocasionados por esse empreendimento. Os dados foram tabulados em planilha do Excel 2019® e analisados de forma qualitativa e quantitativa. De acordo com os resultados obtidos, 70\% dos entrevistados indicaram que a ETE apresentou impactos negativos, como: aumento da proliferação de insetos, do mau cheiro, além da maior incidência de doenças nas áreas situadas próximas a ETE. Nesse sentido, a implementação da ETE trouxe impactos negativos no âmbito socioambiental, sendo que o grau de proximidade das residências dos entrevistados com relação à ETE foi determinante na classificação desses impactos.

Palavras-chave: Saneamento básico; Geração de resíduos; Qualidade ambiental; Gestão ambiental.

\footnotetext{
Abstract

The present research aims to identify the positive and/or negative impacts resulting from the implementation of a Sewage Treatment Plant (STP) from the perspective of the surrounding community in the municipality of Sumé, Paraíba. To this end, the STP was chosen for its relevance in the social/local scenario, since this enterprise has the potential to generate social and environmental impacts. The study area was delimited considering the radius of $1 \mathrm{~km}$ around the STP, in order to characterize the number of residences that make up the neighborhood. The residences
} 
evaluated are located at different strategic points, as a way to ascertain their influence on the interviewees' conception according to the place where they live. After delimiting the study's area of coverage, it was possible to apply the questionnaire in the form of a semi-structured interview with the community around the STP, in order to serve as an instrument to assess the perception of the population about the social and environmental impacts caused by this enterprise. The data were tabulated in Excel 2019® spreadsheet and analyzed qualitatively and quantitatively. According to the results obtained, $70 \%$ of the interviewees indicated that the STP presented negative impacts, such as: increase in the proliferation of insects, bad smell, and a higher incidence of diseases in the areas close to the STP. In this sense, the implementation of the STP brought negative impacts on the socio-environmental sphere, and the degree of proximity of the respondents' homes to the STP was crucial in the classification of these impacts.

Keywords: Basic sanitation; Waste generation; Environmental quality; Environmental management.

\section{Resumen}

Esta investigación tiene como objetivo identificar los impactos positivos y/o negativos derivados de la implantación de una Planta de Tratamiento de Aguas Residuales (PTAR) desde la perspectiva de la comunidad circundante en el municipio de Sumé, Paraíba. Para esto, se ha elegido la PTAR por su relevancia en el escenario social/local, dado que este emprendimiento tiene el potencial de generar impactos sociales y ambientales. La zona de estudio se delimitó considerando el radio de $1 \mathrm{~km}$ alrededor de la PTAR, con el fin de caracterizar el número de viviendas que componen el barrio. Las viviendas evaluadas están situadas en diferentes puntos estratégicos, como forma de conocer su influencia en la concepción de los entrevistados según el lugar donde viven. Después de la delimitación del área de cobertura del estudio, fue posible aplicar el cuestionario en forma de entrevista semiestructurada a la comunidad del entorno de la PTAR, con el fin de que sirviera de instrumento para evaluar la percepción de la población sobre los impactos sociales y ambientales causados por esta empresa. Los datos se tabularon en la hoja de cálculo Excel $2019 \AA$ y se analizaron cualitativa y cuantitativamente. Según los resultados obtenidos, el $70 \%$ de los entrevistados indicaron que la PTAR tenía impactos negativos, tales como: mayor proliferación de insectos, mal olor y mayor incidencia de enfermedades en las zonas cercanas a la PTAR. En este sentido, la implantación de la PTAR trajo consigo impactos negativos en el ámbito socioambiental, siendo el grado de proximidad de las viviendas de los encuestados a la PTAR un factor determinante en la clasificación de estos impactos.

Palabras clave: Saneamiento básico; Generación de resíduos; Calidad ambiental; Gestión ambiental.

\section{Introdução}

Nos últimos anos as preocupações com a qualidade de água e o lançamento do esgoto vêm se intensificando gradativamente principalmente no que tange os efeitos danosos causados ao homem e ao meio ambiente. No Brasil, no que se refere aos serviços de água e esgotamento sanitário, o país abarca uma rede de abastecimento de água vista como abrangente, realidade oposta é verificada na coleta de esgoto, que se encontra deficitária no que concerne à coleta e ao seu tratamento (Ferreira \& Garcia, 2017).

O crescimento urbano e o desenvolvimento tecnológico trazem como consequência imediata o aumento de consumo de água e a ampliação constante do volume de água residuária. Em muitas cidades, parcela significativa da população é atendida por redes coletoras que efetuam o afastamento dos esgotos das proximidades das casas; no entanto, não é realizado qualquer tipo de tratamento para a sua devolução ao meio ambiente e acabam, da mesma maneira, contaminando o solo, os rios, os lagos, os oceanos, as águas subterrâneas e até mesmo mananciais que abastecem outras cidades. Ainda é muito baixo no Brasil o número de municípios que possuem sistemas completos de esgotamento sanitário contemplando a rede coletora e tratamento, além do que muitos dos sistemas existentes atendem apenas a uma parcela destas cidades (FUNASA, 2015).

Na região nordeste dos 1974 municípios totalizando uma população de 40,8 milhões de habitantes, 52\% da coleta de esgoto se dá por companhias estaduais e $42 \%$ não tem serviços institucionalizados, o lançamento de esgotos domésticos nos corpos d'água sem adequado tratamento ou em desconformidade com os atuais padrões legais estabelecidos para lançamento de efluentes, resulta em comprometimento da qualidade da água do corpo receptor e pode inviabilizar o atendimento aos usos atuais e futuros dos recursos hídricos a jusante do lançamentos (ANA, 2017).

Esse índice é mais alarmante na região semiárida, pois a universalização dos serviços de coleta de esgoto sanitário está longe de ser uma realidade nesta região, visto que 78,6\% das sedes municipais não dispõem do serviço. Adicionalmente, das sedes municipais $(21,4 \%)$ que contam com o serviço, apenas $43,7 \%$ da população são beneficiados. Do volume de esgoto 
coletado anualmente, menos de $80 \%$ são tratados antes de serem lançados a céu aberto e/ou nos corpos hídricos. Convém destacar que diversas publicações apontam para uma baixa eficiência dos sistemas de tratamento de esgoto operados no Semiárido, visto que a qualidade do efluente não atende, na maioria dos casos, aos padrões exigidos pela resolução do CONAMA $N^{\circ} 430 / 2011$ que estabelece os padrões para lançamento de esgoto sanitário tratado em corpo hídrico receptor (Medeiros et al., 2014; Brasil, 2011).

A utilização de Estações de Tratamentos de Esgotos (ETE's) é uma alternativa viável para mitigar os problemas relacionados à falta de saneamento básico. Segundo Abdelmoneim et al. (2017), as ETE’s são definidas como estruturas e acessórios que recebem esgoto bruto e provocam uma diminuição da matéria orgânica e bacteriana dos resíduos, tornando-os menos prejudiciais, além de reduzirem o forte odor. O tratamento destina-se a separar da água as matérias orgânica e inorgânica nela contidas antes de devolvê-la ao meio ambiente (Proença et al., 2016).

Tendo em vista os diversos usos dos corpos hídricos, o lançamento e a diluição de efluentes requerem alerta e assistência adequados por parte dos órgãos gestores, a partir da supervisão dos efluentes e do impacto na qualidade da água no corpo receptor. Deve-se impedir a propagação de cargas poluidoras que extrapole a sua capacidade de autodepuração, uma vez que o volume de diluição de um corpo receptor precisa atender aos requisitos iniciais da qualidade e a alteração do regime hidrológico (Marçal \& Silva, 2017).

Apesar da grande importância dos tratamentos de esgotos, sanitários ou industriais, dentro de toda a cadeia de saneamento, as ETE's podem ser grande geradoras de poluição. Elas consomem grandes quantidades de água e de energia, produzem despejos líquidos, liberam diversos gases nocivos para a atmosfera e produzem resíduos sólidos de difícil tratamento e disposição. Em decorrência de tais fatos as ETE's podem ser, e muitas vezes são, um grande problema para o meio ambiente, pois tem potencial para afetá-lo em todos os níveis: ar, água e solo (Lins, 2010).

Diversos estudos têm sido realizados para avaliar os impactos que podem ser ocasionados pela a adoção das distintas técnicas de tratamento de esgotos e, consequentemente, os possíveis efeitos para os setores ambientais e econômicos. No entanto, quando se trata da temática social, a abordagem dos impactos relativos a ETE, tem ocorrido de modo mais restrito, porém é extremamente importante pontuar os impactos positivos e/ou negativos que podem ser gerados para a comunidade que circunda a área de abrangência desse empreendimento. Nesse contexto, a pesquisa tem por objetivo identificar os impactos positivos e/ou negativos decorrentes da implantação da Estação de Tratamento de Esgoto (ETE) sob a perspectiva da comunidade circunvizinha no município de Sumé-PB.

\section{Metodologia}

\subsection{Caracterização da área}

A Estação de Tratamento de Esgoto (Figura 1) localiza-se no município de Sumé-PB, que possui uma área aproximada de $838,058 \mathrm{~km}^{2}$, cerca de 1,53\% da área do Estado Paraibano. Está situado na microrregião do Cariri Ocidental Paraibano, com altitude média de 533m, coordenadas geográficas 7040'13"' latitude sul, 36 52 '58', longitude oeste. 
Figura 1. Imagem do município de Sumé-PB com destaque para localização da estação de tratamento de esgoto.

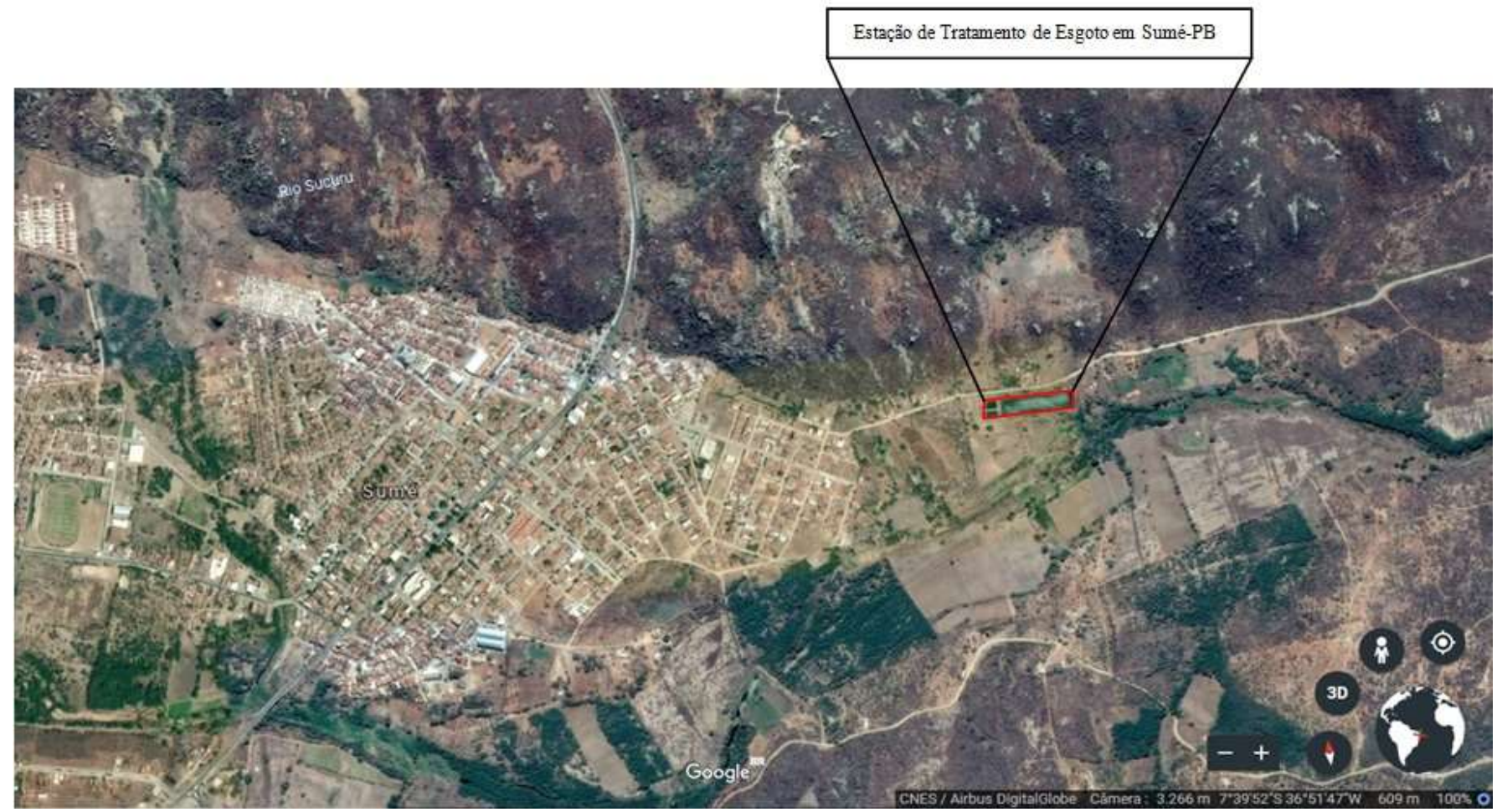

Fonte: Google Earth (2019).

Tendo como municípios limítrofes, na região Norte, situa-se o município de São José dos Cordeiros, na região Sul limitam-se com os municípios de Camalaú e Monteiro, enquanto que na região Leste fazem parte os municípios de Serra Branca e Congo e na região oeste os municípios de Ouro Velho, Prata e Amparo (IBGE, 2010). De acordo com essa última fonte a população sumeense é de aproximadamente 16.072 habitantes.

O principal rio da região é o Sucuru com nascente na cordilheira dos Cariris Velhos, a $5 \mathrm{~km}$ de distância da cidade de Ouro Velho; seu percurso de oeste/leste é interrompido pelo açude de Sumé a $2 \mathrm{~km}$ do município de mesmo nome; apresenta como principais afluentes os: Riacho da Prata, Jureminha, Salgadinho, Olho D'água e São Francisco (Alencar, 2008).

\subsection{Clima}

De acordo com a classificação de Gaussen a área em estudo está sob a influência dos seguintes tipos climáticos: 4aTh (tropical quente de seca acentuada), $2 \mathrm{~b}$ (subdesértico quente de tendência tropical) e 3aTh (mediterrâneo quente ou nordestino de seca acentuada). Não obstante, de acordo com a classificação de Köppen, o clima predominante na região é do tipo Bsh (semiárido quente), com precipitações médias anuais baixas (em torno de $400 \mathrm{~mm}$ ) com estação seca que pode atingir até 11 meses. O índice de aridez (IA) de Thornthwaite para a bacia do Sucuru é de 0,22, que caracteriza o seu clima como semiárido (Alencar, 2008).

Considerando os meses com maior intensidade de chuvas, assim como os meses com menores precipitações pluviométricas, verifica-se que para a região do Cariri paraibano o trimestre chuvoso está relacionado com os meses de fevereiro-março-abril, já para o período trimestral mais seco compreende os meses de agosto-setembro-novembro (Sena, Lucena \& Ribeiro, 2017).

\subsection{Geologia}

Para Silva (1994), a geologia da região está representada pelo complexo gnaissico-migmatito e rochas granitóides, do pré-cambriano indiviso e do período quaternário, por sedimentos aluviais. A área de estudo compreende o Planalto da 
Borborema, correspondente à unidade morfológica Superfície do Planalto ou Superfície dos Cariris, apresentando domínio de relevo suave ondulado e ondulado, com altitudes variando de 380 a $500 \mathrm{~m}$ (Alencar, 2008).

\subsection{Vegetação}

Na região de estudo predomina a caatinga hiperxerófila de porte arbóreo baixo ou arbóreo arbustivo. A vegetação da caatinga possui alta capacidade de adaptação à escassez hídrica, uma vez que seus recursos bioquímicos e físicos a tornam altamente adaptada aos longos períodos de estiagem da região (Ribeiro, 2014).

\subsection{Solos}

De acordo com Francisco (2010), na área ocorrem os Neossolos Litólicos Eutróficos, fase pedregosa substrato gnaisse e granito, e os Vertissolos apresentando relevo suave ondulado e ondulado, predominantemente nas partes mais baixas no entorno da drenagem, e os Planossolos Nátricos, relevo plano e suave ondulado, e a predominância de solos Luvissolos Crômicos bem desenvolvidos, em relevo suave ondulado.

\subsection{Atividades econômicas}

As atividades agrícolas se baseiam na agricultura familiar com o plantio de espécies como feijão macassá ou de corda (Vigna unguiculata) e o milho (Zea mays), ainda nas culturas de batata-doce, fava, algodão herbáceo, mamona, mandioca, tomate, feijão, banana, coco, goiaba, manga e sisal. A pecuária está embasada na criação extensiva de rebanhos, por ordem de importância: caprino, bovino, ovino, suíno, equino, asinino e muares (Alencar, 2008).

\subsection{Método de avaliação dos dados}

A ETE do município de Sumé-PB foi escolhida tendo em vista sua relevância no cenário social/local e sua influência na preservação da qualidade ambiental, por possuir um elevado potencial de geração de impactos em termos sociais e ambientais. A área de estudo foi delimitada considerando-se o raio de $1 \mathrm{~km}$ ao entorno da estação, com o intuito de caracterizar o número de residências que compõe a vizinhança, obtendo-se assim um total de 10 residências próximas ao empreendimento, sendo entrevistado apenas um residente por domicílio.

O valor do raio foi definido de acordo com o método proposto por Giuliano e Giuliano (2004), que propuseram avaliar a área de maior proximidade da ETE, considerando inclusive a vizinhança localizada à jusante da estação. As residências avaliadas encontram-se situadas em diferentes pontos estratégicos, localizadas no início, meio e final da estação, como forma de averiguar a sua influência na concepção dos entrevistados em função do local em que residem.

Para o desenvolvimento da referida pesquisa, a metodologia adotada foi a descritiva, que conforme Vergara (2000), consiste na exposição das características de determinada população ou fenômeno. $\mathrm{O}$ instrumento da pesquisa baseia-se na aplicação de questionário sob a forma de entrevista semiestruturada junto à comunidade circunvizinha da ETE pertencente ao município de Sumé, de modo, a avaliar a percepção da comunidade acerca dos impactos socioambientais ocasionados por esse empreendimento.

$\mathrm{Na}$ elaboração dos questionamentos, foram elencados os principais impactos ocorridos nas fases de implantação e operação da ETE, conforme proposto por Souza e Salvador (1997), descritos na Tabela 1. Fez-se o uso de questões fechadas, tendo como opções respostas dicotômicas, no qual o respondente deveria optar por umas das opções (sim ou não), que foram previamente apresentadas. 
Tabela 1. Descrição dos impactos ocorridos nas fases de implantação e operação da ETE.

\begin{tabular}{cc}
\hline Fase & Impactos \\
\hline \hline Implantação & Ruídos \\
\hline Operação & Desvalorização dos imóveis \\
\cline { 2 - 2 } & Proliferação de insetos \\
\cline { 2 - 2 } & Odores ofensivos \\
\cline { 2 - 2 } & Survimento de doenças \\
\hline
\end{tabular}

Fonte: Autores, com base em Souza e Salvador (1997).

Os moradores foram, previamente, esclarecidos sobre o objetivo do estudo, onde receberam informações pertinentes a procedência, finalidade, assunto tratado e contato dos pesquisadores. Posteriormente, os moradores que concordaram em participar da pesquisa foram entrevistados. As entrevistas foram realizadas nos finais de semana, uma vez que era mais provável que os moradores estivessem em suas residências, além de possuírem maior disponibilidade de tempo. Em relação aos entrevistados, foi garantido aos mesmos o anonimato no que tange a sua identidade, para que pudessem responder ao questionário sem nenhum tipo de constrangimento, sendo caracterizados socialmente com relação ao gênero, faixa etária e nível de escolaridade. Os dados foram tabulados em planilha eletrônica do Excel 2019® e analisados de forma qualitativa e quantitativa.

\section{Resultados e Discussão}

Foram entrevistados 10 residentes, domiciliados nas proximidades da ETE situada no município de Sumé, verificouse que a maioria entrevistados, correspondentes a $80 \%$, pertenciam ao sexo feminino, enquanto, que o sexo masculino representou apenas $20 \%$ dos entrevistados. Isto provavelmente está relacionado ao fato de que a maior parte das mulheres são responsáveis pelas atividades domésticas, contribuindo assim, para a maior representatividade feminina no momento da entrevista. Quanto a faixa etária dos respondentes, as maiores expressividades foram observadas para as faixas de 30 a 41 e 42 a 53, ambas com 30\%. As faixas etárias de 18 a 29 e 54 a 65 obtiveram o mesmo percentual, de $20 \%$, respectivamente.

Com relação ao nível de escolaridade dos entrevistados, constatou-se que $40 \%$ destes não possuíam ensino fundamental completo; $20 \%$ apresentavam ensino médio completo, bem como, os entrevistados que possuíam o nível de pósgraduação. Os níveis de escolaridade caracterizados como não alfabetizado e ensino médio incompleto, corresponderam cada um a $10 \%$, do total dos residentes avaliados.

A Figura 2 corresponde ao percentual dos entrevistados com relação à implementação da ETE, se a mesma foi vista de forma positiva ou negativa pela população circunvizinha. 
Figura 2. Percepção dos entrevistados em relação à instalação da ETE.

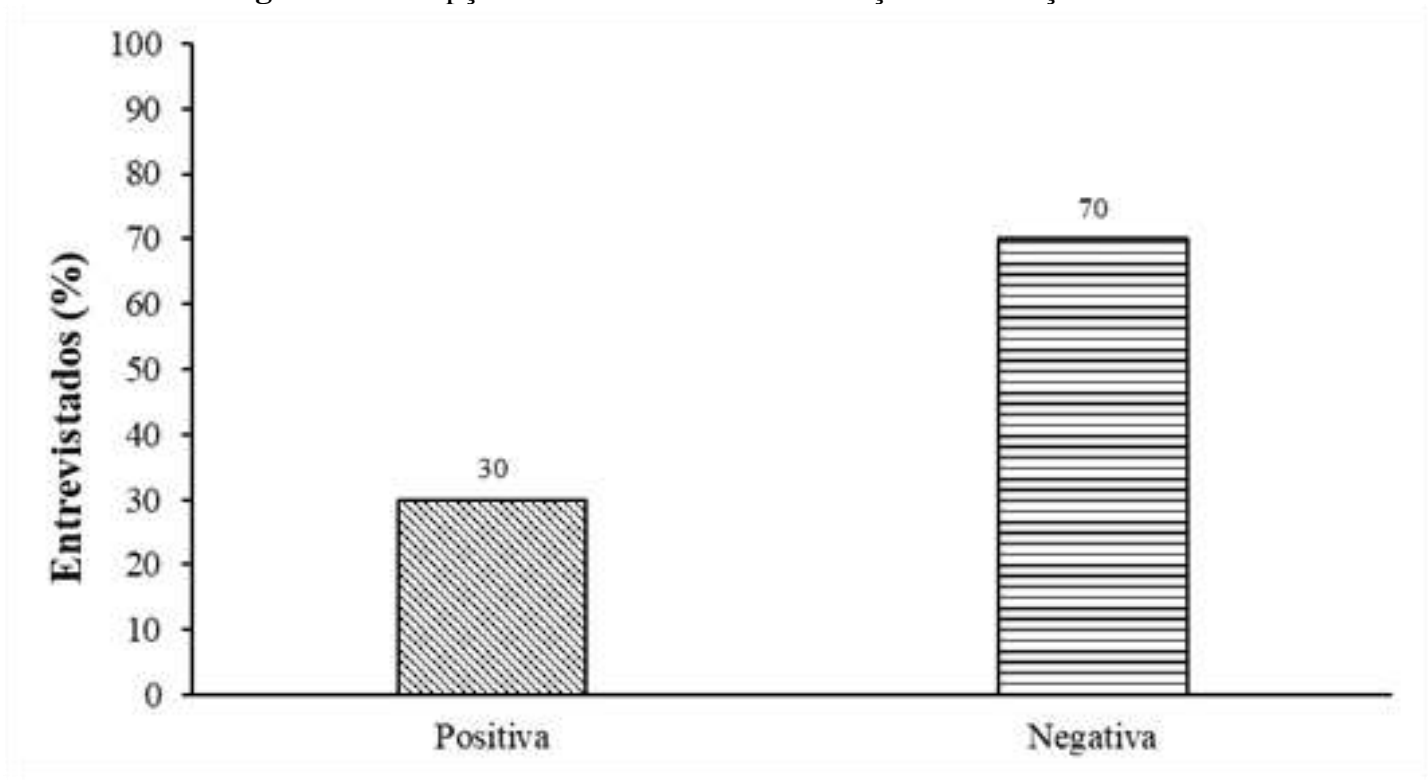

Fonte: Autores (2020).

Assim, observou-se que 70\% dos entrevistados classificaram a implementação da ETE como impacto negativo para a comunidade circunvizinha. Nesse contexto, para Castanheira e Baydum (2015), os principais malefícios com relação à implantação de ETE's diz respeito a proliferação de insetos, odores fortes, aumento do tráfego e incômodos em geral, além da desvalorização dos imóveis no entorno da estação.

Entretanto, $30 \%$ dos entrevistados consideraram benéfica a instalação da ETE, pois estes apontaram que o esgoto não ficaria a céu aberto. Mediante CESAN (2013), com a implantação da ETE a ocorrência de doenças diminui e isso beneficia principalmente as crianças, uma vez que a falta de saneamento básico ocasiona doenças como: diarreia infecciosa, cólera, leptospirose e esquistossomose. Ademais, além de diminuir a incidência de doenças, as ETE’s são de suma importância, visto que a água é um recurso essencial para o suprimento do homem e dos seres vivos, como também ajuda a manter a cidade com uma melhor qualidade de vida (Castanheira \& Baydum, 2015).

A Figura 3 apresenta a percepção da população circunvizinha em relação aos ruídos resultantes da construção/operação da ETE no município de Sumé-PB. 
Figura 3. Problemas com a geração de ruídos oriundos da implantação de ETE.

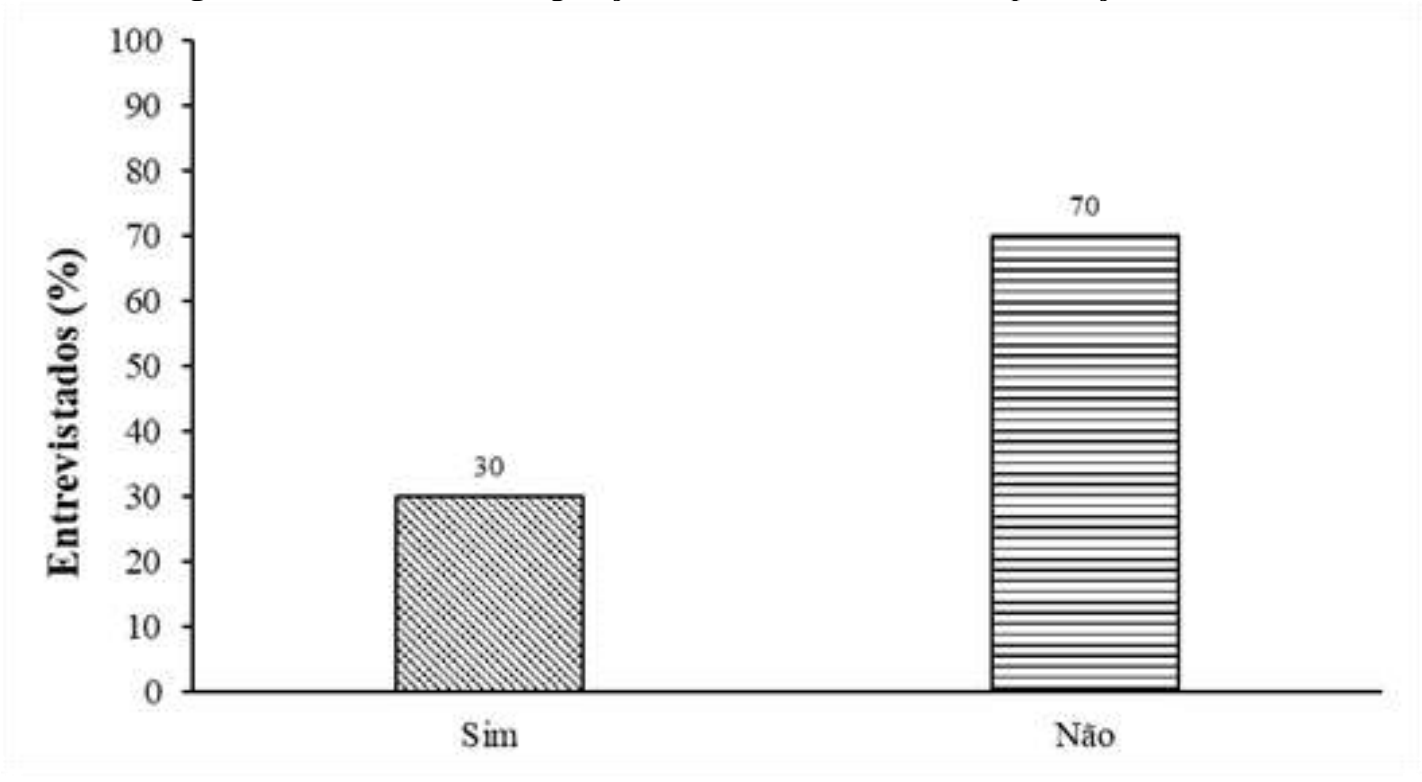

Fonte: Autores (2020).

Com relação aos problemas com ruídos na fase de implantação (Figura 3) notou-se que 70\% dos entrevistados não sofreram com tal problemática, uma vez que estes mencionaram que não residiam no entorno da ETE no período da implantação. Castanheira e Baydum (2015) avaliando impactos de ETE no bairro de Cajueiro Seco em Jaboatão dos Guararapes, observaram resultados opostos com relação aos ruídos, uma vez que $90 \%$ dos entrevistados apontaram que houve a presença de ruídos com relação à instalação da estação. A discordância entre os resultados obtidos nos estudos é justificável, visto que, no estudo conseguinte, os entrevistados residiam na área previamente a implantação da ETE.

A Figura 4 aborda os problemas relacionados ao aparecimento de insetos resultantes da implantação da ETE sob a perspectiva da população circunvizinha.

Figura 4. Surgimento de insetos provenientes da instalação da ETE.

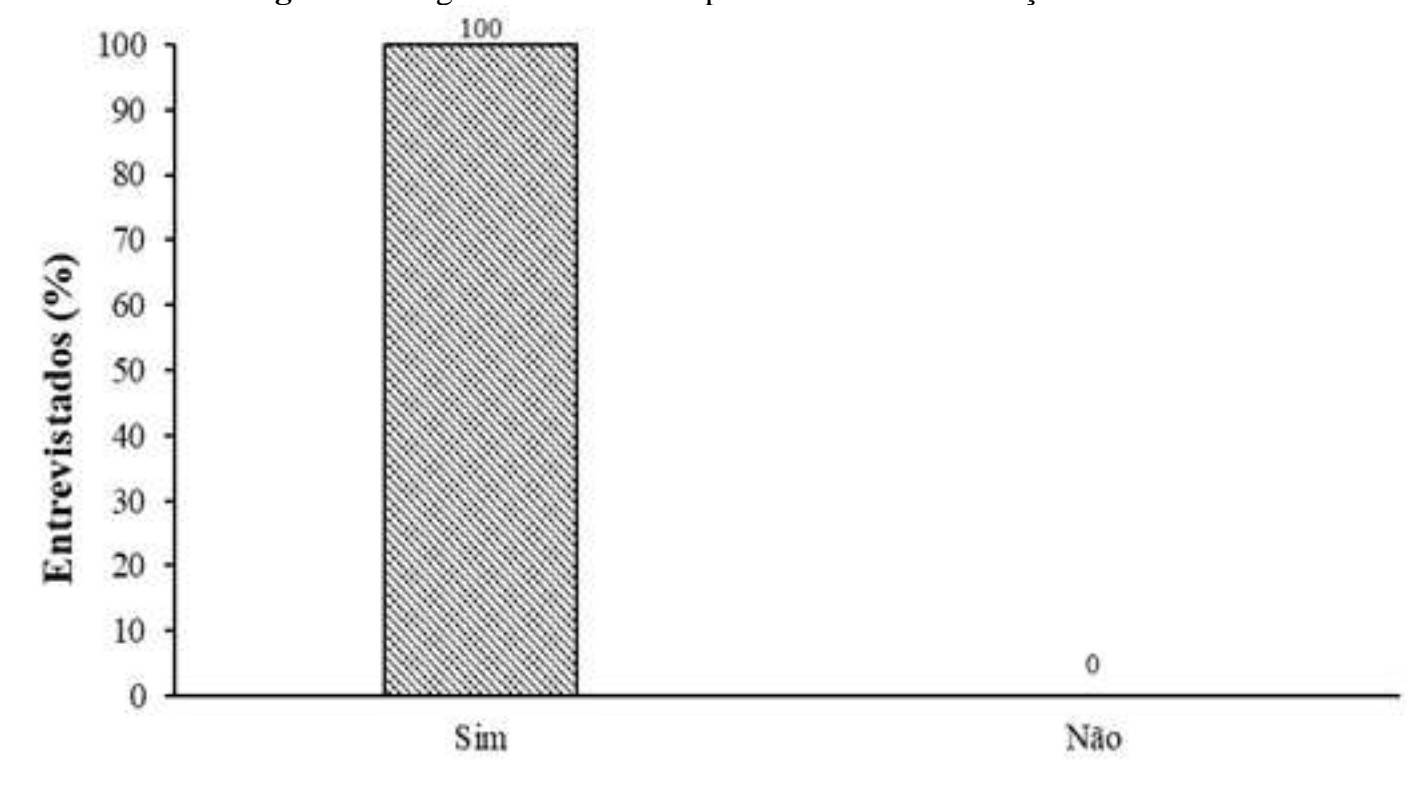

Fonte: Autores (2020).

Em relação a Figura 4, verifica-se que $100 \%$ dos entrevistados apontaram para o aumento da proliferação de insetos com a instalação da ETE, principalmente de baratas e mosquitos em suas residências. Tal fato, provavelmente está relacionado 
a técnica de tratamento de esgoto adotada na ETE, no qual realiza-se apenas o tratamento preliminar, que segundo La Rovere (2002), compreende apenas o processo físico que é utilizado para remover sólidos grosseiros e partículas de areia, com a finalidade de evitar a abrasão dos rotores e das bombas.

Para Vaz et al. (2003), a remoção e coleta dos sólidos grosseiros, reflete positivamente no meio físico, biótico e antrópico modificando a qualidade da água, beneficiando a manutenção e/ou melhoria do meio físico, a fauna e flora terrestre, alada e aquática, e em consequência, a melhoria da qualidade de vida, além de diminuir o conflito de uso das águas. Entretanto, o tratamento preliminar consegue atingir um percentual de remoção baixo, portanto, o lançamento destes efluentes em corpo receptor altera de maneira significativa a qualidade de água, a microbiota aquática, além de problemas como eutrofização. Sendo assim, a possível medida para a diminuição dessa problemática, seria a adoção do tratamento secundário, visto que esse tratamento tem como finalidade promover a remoção da matéria orgânica, que de acordo com Sanesalto (2016), é a grande causadora do aumento do número de insetos em uma região.

O percentual dos entrevistados com relação à presença de odores fortes no entorno da ETE sob a ótica da população vizinha, encontra-se representado na Figura 5.

Figura 5. Problemas relacionados aos odores mediante instalação da ETE.

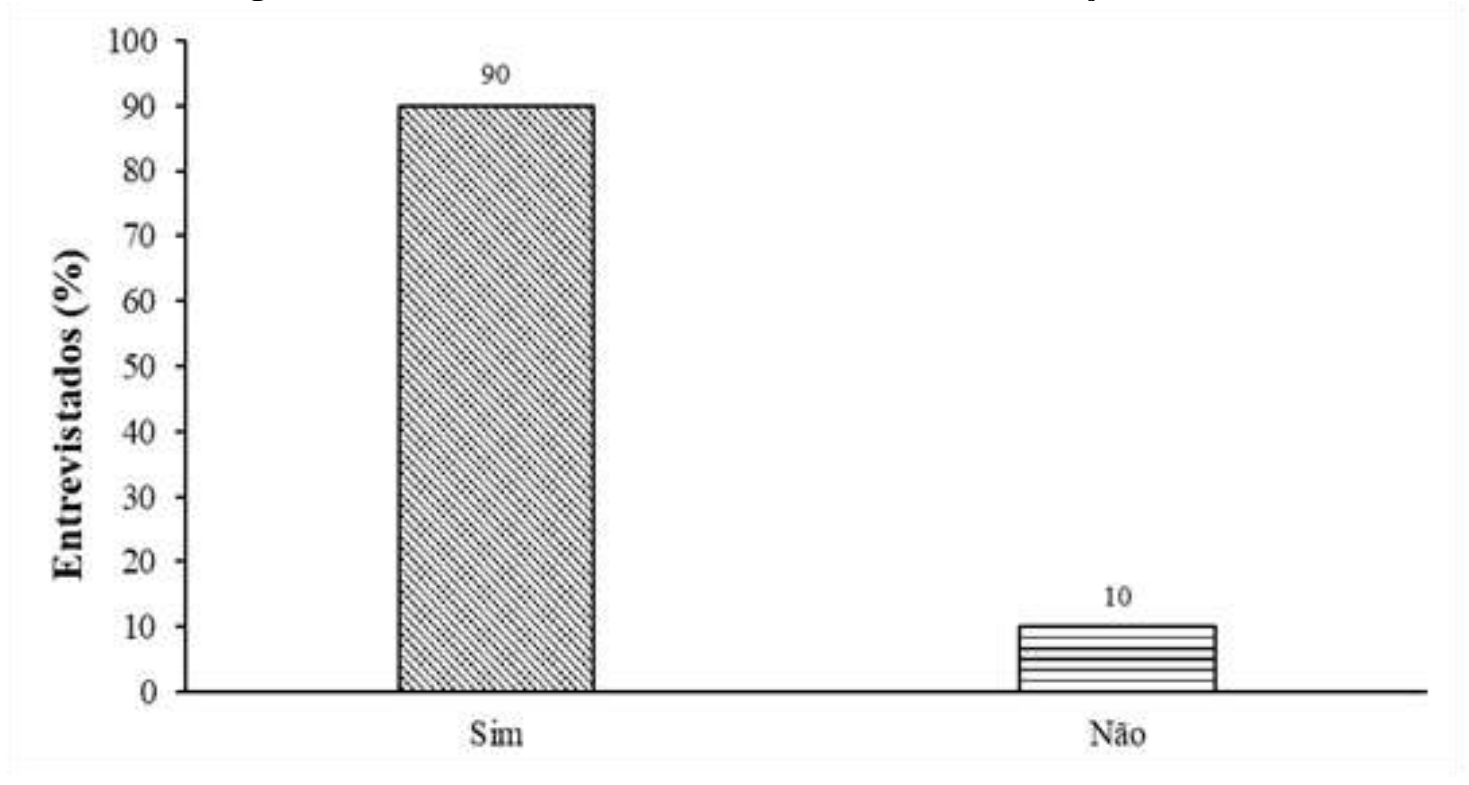

Fonte: Autores (2020).

Constata-se que $90 \%$ dos entrevistados mencionaram a presença de odores fortes na área circunvizinha a ETE, principalmente no período da tarde. Em consonância com a referida pesquisa, Castanheira e Baydum (2015), avaliando os impactos ambientais oriundos da ETE de Jaboatão dos Guararapes - PE, observaram que 95\% das pessoas entrevistadas se sentiam incomodadas com o mau cheiro e relataram que o odor era intensificado no verão. Muito provavelmente, isto pode ser explicado devido a influência do tipo de tratamento adotado na ETE deste município, todavia esta informação não foi especificada pelos autores. Contudo, $10 \%$ da população entrevistada relataram que não sofrem com tal problemática, visto que as residências estão situadas no final da ETE e no sentido favorável a circulação do vento, promovendo a dissipação do odor, por este vetor. Para Drew et al. (2007), apontam para os fatores como estação do ano, horário do dia e condições atmosféricas, como influenciadores da dispersão dos odores (turbulência, direção e velocidade do vento).

Consoante a isto, a ocorrência de maus odores no entorno das estações, afeta toda a população circunvizinha, em virtude do gás sulfídrico, principal poluente odorífero em ETE’s (Liu, 2021), gerando constantes reclamações por parte da vizinhança, além de ser potencialmente perigoso para os operadores das ETE's devido ao alto potencial de toxicidade. A 
Agência de Proteção Ambiental Americana (EPA, 2016), aponta que existem diversas formas de toxicidade deste gás nos seres humanos, podendo afetar a visão, o olfato e o tato, além disto, quando as concentrações ultrapassam 10 ppm, podem resultar em danos a saúde humana a curto, médio e longo prazo.

De acordo com Capelli et al. (2012) os odores emitidos pelas ETE’s não são cancerígenos, contudo, sua presença no ar costuma ter um efeito prejudicial com relação às pessoas no que tange sintomas de dor de cabeça e tontura, mal estar, problemas de concentração ou outros riscos à saúde. Além disso, sua emissão tem um efeito negativo no ecossistema vegetal e animal (Nicell, 2009). Segundo Gebicki, Byliński e Namieśnik (2015) o nível de emissão desses compostos para o meio ambiente é variável e depende em grande parte da qualidade do esgoto, da taxa de alterações biológicas ocorridas no esgoto coletado ou das soluções tecnológicas empregadas nas ETE's.

Na Figura 6 têm-se a percepção da população local no que diz respeito a desvalorização dos imóveis próximos a ETE.

Figura 6. Avaliação da desvalorização dos imóveis próximos a ETE.

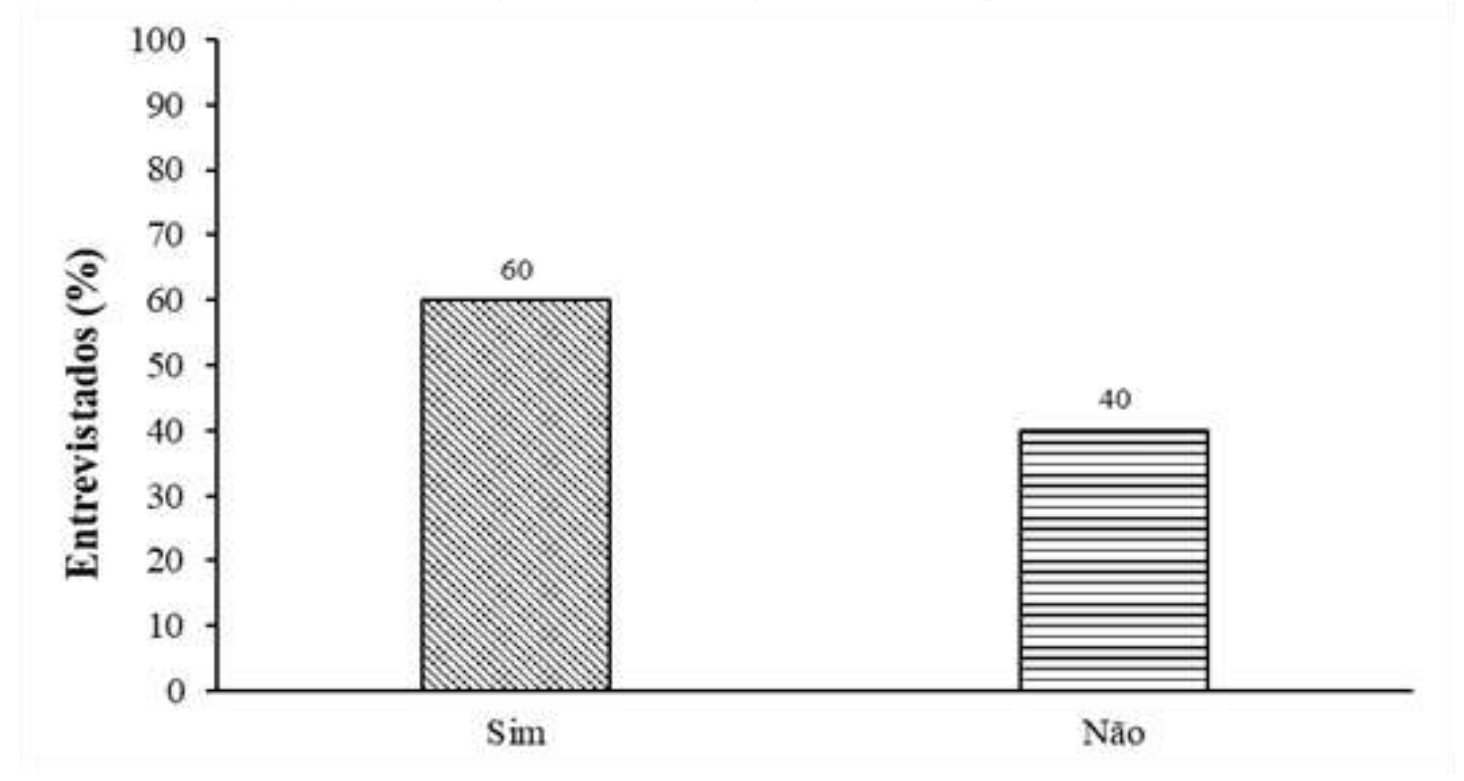

Fonte: Autores (2020).

A desvalorização do imóvel em virtude da proximidade da ETE, foi considerada por $60 \%$ dos entrevistados, como um dos impactos negativos referentes a implantação da estação. No entanto, $40 \%$ dos respondentes relataram que não ocorreu desvalorização, uma vez que suas residências se encontram situadas em áreas de maior distanciamento do empreendimento, quando comparadas aos demais domicílios avaliados que são diretamente afetados em função da proximidade com a área da estação. Silva (2007), analisando a população vizinha a ETE localizada no Paranoá - DF, constatou que o processo de venda dos imóveis foi dificultado, por estarem situados próximos a área de influência da estação. No entanto, em pesquisa realizada por Brito (2010), contrariamente ao resultado identificado neste estudo, foi verificado que a presença da ETE provocou valorização imobiliária na visão dos moradores e corretores, em virtude do processo de revitalização realizado na ETE pertencente ao município de Lagoa Encantada - BA.

A Figura 7, abrange os problemas relacionados ao surgimento de doenças resultantes da implantação da ETE sob a visão da população circunvizinha. 
Figura 7. Verificação do surgimento de doenças oriundas pela ETE.

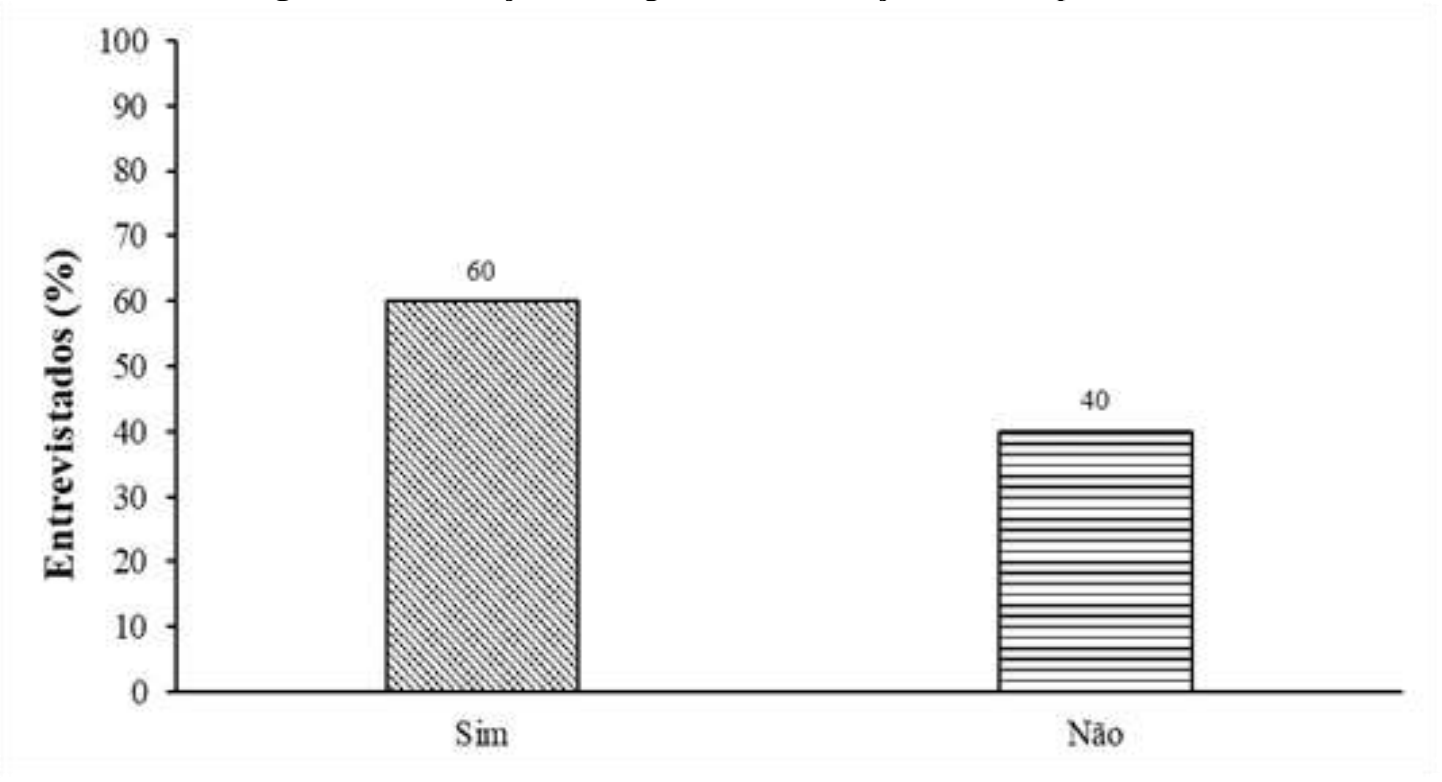

Fonte: Autores (2020).

No que tange ao surgimento de doenças provocadas pela implantação da ETE, 60\% dos entrevistados concordaram que houve influência negativa da ETE, favorecendo o surgimento de casos de doenças, tais como: gripe, tosse e infecção intestinal, sendo as crianças mais acometidas por essas doenças. Para os demais entrevistados (40\%), foi relatado que não houve o surgimento de doenças, uma vez que essas residências se encontram mais distanciadas da área de influência da ETE.

Abdelmoneim et al. (2017), ao realizarem estudo sobre os perigos para a saúde relacionados à estação de tratamento de esgoto de Soba - Sudão, verificaram que 83,3 \% dos entrevistados de um total de 412 pessoas, apontaram que as principais doenças relacionadas a ETE's foram problemas psicológicos (91,2\%) como desconforto e irritabilidade, problemas respiratórios $(62,6 \%)$ como tosse, falta de ar e chiado no peito, além de problemas gastrointestinais (61\%) como náuseas e diarreias. Vale destacar a constatação de doenças do tipo gastrointestinais no artigo citado, corroborando com essa pesquisa que também registrou casos dessa natureza.

Na Figura 8, têm-se o posicionamento dos entrevistados com relação ao aumento das tarifas de serviços de saneamento básico, após a implantação da ETE. 
Figura 8. Constatação do aumento das tarifas de saneamento básico após a ETE.

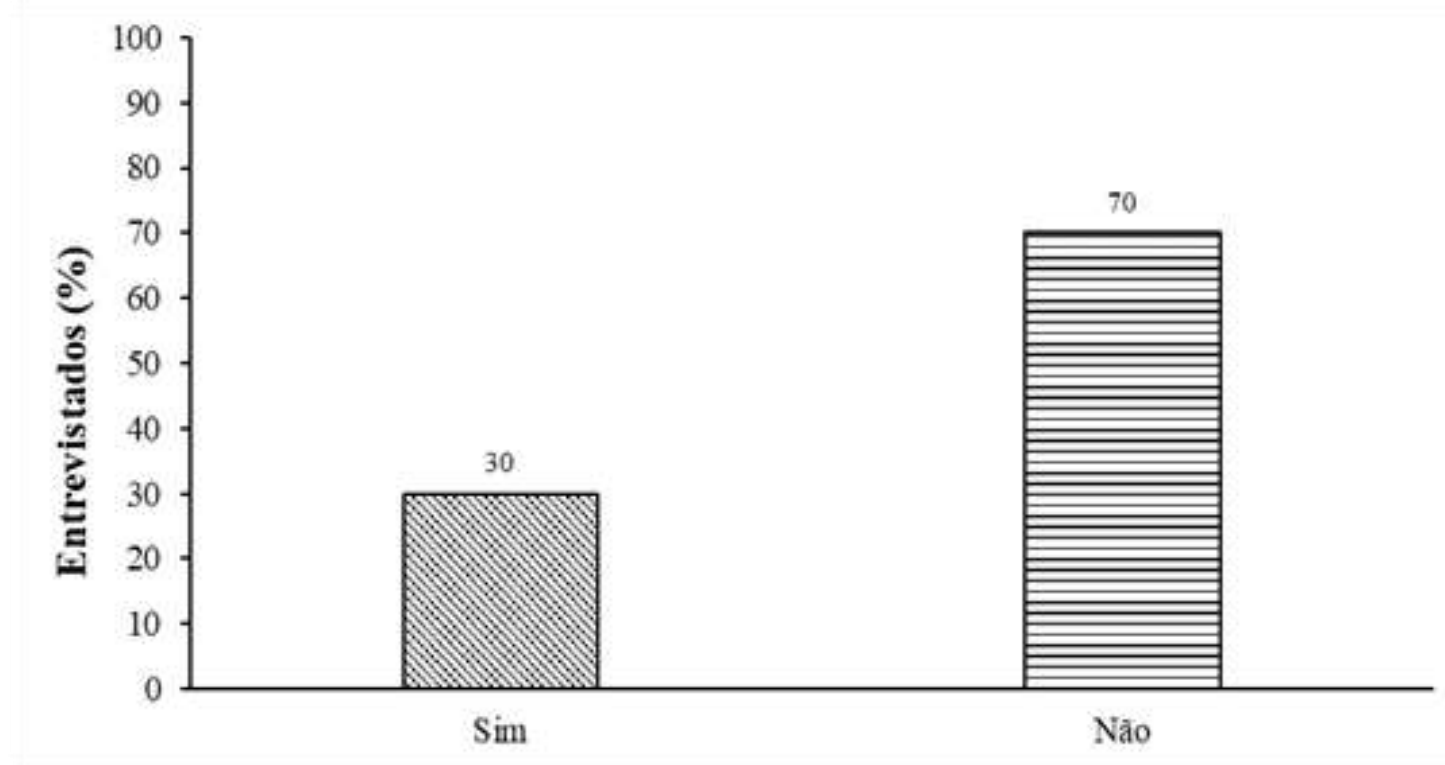

Fonte: Autores (2020).

Com relação ao aumento das tarifas de serviços de saneamento básico, a maior parcela dos entrevistados, correspondente a $70 \%$, responderam que não houve acréscimo nas taxas de saneamento, possivelmente, por residirem na zona rural do município, pois, de modo geral, verifica-se uma redução tarifária para as residências localizadas na área rural. É importante ressaltar, que parte destes respondentes, não souberam informar se ocorreu alterações dos valores das tarifas de saneamento após a implantação da ETE. Contudo, 30\% dos respondentes, afirmaram que houve acréscimo das tarifas, neste caso os domicílios estão situados na zona urbana do município de Sumé. De acordo com a Resolução CONAMA 430/2011 (Brasil, 2011), cabe ressaltar que a tarifa pelo esgoto é em relação à porcentagem de esgoto tratado, incluindo o tratamento e o lançamento em corpos hídricos.

\section{Conclusão}

O instrumento de estudo, permitiu verificar que a população residente nas proximidades da ETE, é composta prioritariamente por famílias que apresentam baixo desenvolvimento socioeconômico, com suas atividades essencialmente domésticas ou voltadas para a subsistência, notadamente, uma característica dominante do cenário de grande parte da população que compõe a região semiárida da Paraíba.

De acordo com os resultados obtidos, evidencia-se que a Estação de Tratamento de Esgoto (ETE) propiciou o surgimento de impactos negativos no âmbito socioambiental, deve-se ressaltar, que o nível de proximidade das residências dos entrevistados com relação à ETE, foi um fator preponderante no processo de classificação desses impactos.

Na perspectiva da maioria dos entrevistados a instalação da ETE contribuiu para o surgimento de impactos negativos, tais como: proliferação de insetos, odores fétidos na área, aumento de casos de doenças de origem respiratória e gastrointestinais, além, da desvalorização dos imóveis localizados nas áreas de maior proximidade do empreendimento. Com relação aos impactos positivos, pode-se enfatizar a importância do tratamento de esgoto, como forma de evitar e/ou reduzir a poluição da água, do ar e do solo, proporcionando substancialmente uma melhoria da qualidade de vida.

As percepções da população elencadas nesta pesquisa, denotam a necessidade de um planejamento adequado que contemple todas as etapas imprescindíveis para o funcionamento da ETE, de modo a mitigar os possíveis impactos negativos nos setores sociais, econômicos e ambientais. Ademais, sugere-se a implementação de tratamento secundário na ETE em estudo com a finalidade de mitigar os problemas resultantes deste empreendimento, a exemplo de odores e proliferação de insetos. 


\section{Referências}

Abdelmoneim, R. O. A., Mahdi, R. M. M. E., Elahmer, R. M. E., Elansary, R. A. D., Mohamed, S. E. W., Abdelgader, S. H. A., Ahmed, S. S. A., \& Abdalrhman, S. M. A. (2017). Health hazards related to Soba sewage treatment plant, Sudan. Journal of public health in Africa, 8 (2), $140-143$.

Alencar, M. L. S. (2008). Os sistemas Hídricos, o bioma Caatinga e o Social na bacia do Rio Sucuru: Riscos e Vulnerabilidades. Campina Grande, Tese (Doutorado em Engenharia Agrícola). Universidade Federal de Campina Grande, 157 p.

ANA - Agência Nacional de Águas. (2017). Atlas Esgotos. Brasília, Despoluição de Bacias Hidrográficas, Brasil.

Brasil. Resolução CONAMA Nº 430 de 13 de maio de 2011. (2011). Dispõe sobre as condições e padrões de lançamento de efluentes, complementa e altera a Resolução $n^{\circ}$ 357, de 17 de março de 2005, do Conselho Nacional do Meio Ambiente-CONAMA. Diário Oficial da União. República Federativa do Brasil, Poder Executivo.

Bressane, A., Roveda, J. A. F., Roveda, S. R. M. M., Martins, A. C. G., Reis, F. A. G. V., \& Giordano, L. D. C. (2018). Seleção de alternativas de projeto através de um índice global de impactos ambientais. Geociências, São Paulo, 37 (1), 155-166.

Brito, E. A. T. (2010). Verificação da valorização imobiliária a partir da revitalização da ETE Lagoa Encantada. Cuiabá, Dissertação (mestrado). Universidade Federal de Mato Grosso.

Britto, E. R. (2007). Auditoria Ambiental e em Saneamento. ABES- Associação Brasileira de Engenharia Sanitária e Ambiental.

Capelli, L., Sironi, S., Del Rosso, R., Bianchi, G., \& Davoli, E. (2012). Olfactory and toxic impact of industrial odour emissions. Water Science and Technology, 66, 1399-1406.

Castanheira, J. P. A., \& Baydum, V. P. A. (2015). Percepção dos Impactos Socioambientais da Estação de Tratamento de Esgotos (ETE) Relatados pelos Moradores do Residencial Olho d’Água, Jaboatão dos Guararapes, PE. Revista Brasileira de Geografia Física, 8 (3), $876-887$.

CESAN - Companhia Espírito-santense de Saneamento. (2013). Apostila Tratamento de Esgoto. http://www.cesan.com.br/wpcontent/uploads/2013/ 08/APOSTILA_TRATAMENTO_ESGOTO.pdf

Christodoulou, A., \& Stamatelatou, K. (2016). Overview of legislation on sewage sludge management in developed countries worldwide. Water Science and Technology, 73 (3), 453-462.

Drew. G. H., Smith, R., Gerard, B., Burge, C., Loww, M., Kinnersley, R., Sneat, H. R., \& Lon Ghurst. (2007). Approateness of selecting different averaging times for modeling chronic and acute exposure to environmental odours. Revista Atmospheric Environment, 41, $2870-2880$.

EPA - Environmental Protection Agency of United States. (2021). Secondary Treatment Standards. In: National Pollutant Discharge Elimination System (NPDES). https://translate.google.com.br/translate?hl=pt-BR\&sl=en\&u=https://www.epa.gov/npdes\&prev=search

Ferreira, M. P., \& Garcia, M. S. D. (2017). Saneamento básico: meio ambiente e dignidade humana. Revista Dignidade, 2 (3), 1-12.

Francisco, P. R. M. (2010). Classificação e mapeamento das terras para mecanização do Estado da Paraíba utilizando sistemas de informações geográficas. Areia, Dissertação (Mestrado em Manejo de Solo e Água). Universidade Federal da Paraíba.

FUNASA - Fundação Nacional de Saúde. (2015). Manual de Saneamento. (4a ed.).

Gebicki, J., Byliński, H., \& Namieśnik, J. (2015). Measurement techniques for assessing the olfactory impact of municipal sewage treatment plants. Environmental Monitoring and Assessment, 188, 1-15.

Google Earth. (2019). Imagem de satélite da área da ETE no município de Sumé-PB, 2019. https://earth.google.com/

IBGE - Instituto Brasileiro de Geografia e Estatística. 2010. Histórico e população estimada do Município-2516300. https://censo2010.ibge.gov.br/

La rovere, E. L. (2002). Manual de auditoria ambiental para estações de tratamento de esgotos domésticos.

Leoneti, A. B., Prado, E. L., \& Oliveira, S. V. W. B. (2011). Saneamento básico no Brasil: considerações sobre investimentos e sustentabilidade para o século XXI. Revista de Administração Pública, 45 (2), 331-348.

Lins, G. A. (2010). Avaliação de Impactos em Estação de tratamento de esgotos (ETE). Rio de Janeiro, Dissertação (Mestrado em Engenharia Ambiental). Universidade Federal do Rio de Janeiro.

Liu, Z. (2021). Urban sewage treatment odor gas release characteristics and regional differences. Environmental Technology \& Innovation, $21,101190$.

Marçal, D. A., \& Silva, C. E. (2017). Avaliação do impacto do efluente da estação de tratamento de esgoto ETE-Pirajá sobre o Rio Parnaíba, Teresina (PI). Engenharia Sanitária Ambiental, 22 (4), 761-772.

Medeiros, S. S., Salcedo, I. H., Santos, D. B., Batista, R. O., Santos Júnior, J. A., Lima, R. C. C., \& Marin, A. M. P. (2014). Esgotamento sanitário: panorama para o semiárido brasileiro. Campina Grande. Instituto Nacional do Semiárido.

Nicell, J. A. (2009). Assessment and regulation of odour impacts. Atmospheric Environment, 43, $196-206$.

Proença, H. C., Souza, L. H. P., Jardim, W., Toledo Filho, E. T. L., Felix, A. D. S., \& Reda, A. L. L. (2016). Inovação no tratamento de esgoto em sistema isolado: viabilidade da aplicação da tecnologia Cleartec ${ }^{\circledR}$ num condomínio privado. In: XVI Safety, Health and Environment World Congress, Salvador-Ba, 14-19. Anais do XVI Safety, Health and Environment World Congress, Salvador-BA. 
Research, Society and Development, v. 10, n. 10, e263101018678, 2021

(CC BY 4.0) | ISSN 2525-3409 | DOI: http://dx.doi.org/10.33448/rsd-v10i10.18678

Ribeiro, G. N. (2014). Uso de geotecnologias no estudo da degradação das terras no município de Sumé-PB. Campina Grande, Tese (Doutorado em Engenharia Agrícola). Universidade Federal de Campina Grande.

Sanesalto. (2016). Funcionamento da estação de tratamento de esgoto ST Isabel. Disponível em: http://www.sanesalto.com.br/servicos/tratamento-de-esgoto

Sena, J. P. O., Lucena, D. B., \& Ribeiro, G. N. (2017). Eventos extremos de precipitação no sertão paraibano: Variação espaço-temporal. Revista Verde de Agroecologia e Desenvolvimento Sustentável, 12 (4), 748-755.

Silva, F. H. B. (1994). Caracterização dos Padrões de Drenagem a partir de técnicas de Sensoriamento Remoto para Uso em Levantamentos de reconhecimento (Alta Intensidade) de Solos. Campina Grande, Dissertação (Mestrado em Engenharia Agrícola). Universidade Federal de Campina Grande.

Silva, A. B. (2007). Avaliação da produção de odor na estação de tratamento de esgoto Paranoá e seus problemas associados. Brasília, Dissertação (Mestrado em Tecnologia Ambiental e Recursos Hídricos). Universidade de Brasília.

Silva e Sousa, T. J., Alonso, J. M., Leles, P. S. S., Silva Abel, E. L., Ribeiro, J. G., \& Silva Santana, J. E. (2019). Mudas de Luehea divaricata produzidas com biossólido de duas estações de tratamento de esgoto. Advances in Forestry Science, 6 (2), 595-601.

SNIS - Sistema Nacional de Informações sobre Saneamento. (2016). Diagnóstico dos Serviços de Água e Esgotos - 2014, SNSA/MCIDADES, Ministério das Cidades, Secretaria Nacional de Saneamento Ambiental, Brasília.

Souza, R. C, \& Salvador, N. N. B. (1997). "Proposta para Avaliação dos Impactos Sociais nos Processos de Implantação e Operação dos Serviços de Tratamento de Esgotos Sanitários". Revista Engenharia Sanitária e Ambiental, 2 (3), p. 91-95.

Tavares, F. V. F. (2008). Remoção de surfactantes aniônicos em filtros biológicos percoladores com diferentes meios suporte aplicados ao pós-tratamento de efluentes de reatores UASB. Dissertação (mestrado). Universidade Federal de Minas Gerais.

Vaz, A. P. R., Ducatti, M. L., \& Pasqualetto, A. (2003). Avaliação de impactos ambientais nas estações de tratamento de esgotos sanitários: ETE-Lajes, Aparecida de Goiânia-GO. Serviço Nacional de Aprendizagem Industrial (SENAI), 1, 1-17.

Vergara, S. C. (2000). Projetos e relatórios de pesquisa em administração. (3a ed.), Atlas. 